\title{
Evaluation of Anti-Helicobacter Pylori Activity and Urease Inhibition by Some Turkish Authentic Honeys
}

\author{
Sevgi Kolayl1 ${ }^{1}$, Nimet Baltas ${ }^{2}$, Huseyin Sahin $^{3}$ and Sengul Karaoglu ${ }^{4}$ \\ 1. Department of Chemistry, Faculty of Science, Karadeniz Technical University, Trabzon 61080, Turkey \\ 2. Department of Chemistry, Faculty of Arts and Science, Recep Tayyip Erdogan University, Rize 53100, Turkey \\ 3. Espiye Vocational School, Giresun University, Espiye/Giresun 28600, Turkey \\ 4. Department of Biology, Faculty of Arts and Science, Recep Tayyip Erdogan University, Rize 53100, Turkey
}

\begin{abstract}
Infection with Helicobacter pylori (H. pylori) is an important known risk factor for gastric disease. At least half the world's population is under the influence of this bacterium type. So many therapeutic studies focus on treat gastric disease. But these treatments could be interrupted due to metabolic toxic and show the drug resistance. The objective of this study was to investigate the effecting degree of $H$. pylori with different type of honey samples from Turkey. The study was supported by bioactivity results of total phenolic (TPC) and flavonoid content (TFC). The agar-well diffusion assay was carried out on H. pylori strain J99 and the inhibition zones were measured and compared with standards. Inhibition of $H$. pylori urease as $\mathrm{IC}_{50}$ ranged from $2.67-18.12 \mathrm{mg} / \mathrm{mL}$. These results were supported by TPC and TFC had range from 22.10-79.00 mg Gallic Acid Equivalent (GAE)/100 honey and 0.88-7.08 mg Quercetin Equivalent (QE)/100 g honey, respectively. These results indicate that honey extracts may be appropriate agents to treat $H$. pylori by inhibition effect.
\end{abstract}

Key words: Honey, anti-Helicobacter pylori, urease inhibition, antimicrobial.

\section{Introduction}

Absolutely honey is a valuable food member. The major constituent of honey is carbohydrates that fructose and glucose are the main components. Besides this major content, water, mineral substances and individual bioactive responsible components are in too [1]. Turkey is one of the highly important honey producing countries because of geographical position, climatic conditions and three seasons of the year being suited to honey production [1]. But also, it could not be evaluated as only food. Since ancient times, honey has been used as an alternative medicinal source for treatment of some diseases due to multiple bioactivity properties as antimicrobial, antioxidant, anti-fungal, anti-tumoral, anti-carcinogenic. These properties could be changed by various factors such as floral

Corresponding author: Huseyin Sahin, assist. prof., research fields: bioactivity of natural products (especially bee products and edible or non-edible plants), medicinal chemistry, enzyme inhibition and chromatographic techniques. changing, honey bees types, harvesting style and climate etc. Especially antioxidant and antimicrobial activity of honey depends on various factors, principally the plant source used by the honey bees [2].

Helicobacter pylori, which infected so many people with peptic ulcer disease, mucosa-associated lymphoid tissue (MALT) lymphoma and gastric cancer, is spiral shaped bacteria [3]. There are so many drugs of the production of nitroimidazoles and clarithromycin derivatizations to treat the $H$. pylori and its effects [4, 5]. However, metabolic system is usually inclined to development of drug resistance that is the reduction in effectiveness of a drug curing a disease or condition. Besides drug resistance, non-compliance may be a major cause of treatment failure in patients with the infections.

The reporting includes that $15 \%$ of clinical $H$. pylori isolates develop multidrug resistance, i.e. resistance to three or more antibiotics of different 
classes [3]. Recently, alternative treatment is coming to popular with natural products which as previous time. Honey is one of these natural products has a success rate of anti- $H$. pylori treatment and decreasing the risk of gastric cancer. In the light of this reality, this study includes monofloral honey properties as a natural inhibitor for $H$. pylori and supports the bioactivity situation with total phenolic and total flavonoid results.

\section{Materials and Methods}

\subsection{Chemicals}

Bovine serum albumin, Folin-Ciocalteu phenol reagent, Trolox ${ }^{\circledR}$ (6-hydroxy-2,5,7,8-tetramethyl chroman-2-carboxylic acid), gallic acid, urea, acetohydroxamic acid, ethylene diamine tetra acetic acid (EDTA), lithium chloride ( $\mathrm{LiCl}$ ), phenol, sodium nitroprusside, sodium hydroxide $(\mathrm{NaOH})$, sodium hypochlorite $(\mathrm{NaOCl})$, sodium phosphate dibasic $\left(\mathrm{Na}_{2} \mathrm{HPO}_{4}\right)$, sodium phosphate monobasic monohydrate $\left(\mathrm{NaH}_{2} \mathrm{PO}_{4} \cdot \mathrm{H}_{2} \mathrm{O}\right)$, and quercetin were purchased from Sigma Chemical Co. (St Louis, MO, USA).

\subsection{Honey Sample and Extraction}

Thirteen honey samples were obtained from experienced beekeepers in 2015 from different areas of Turkey. According to the declaration of beekeepers, the samples were dived two categories as honeydew honey and others. Out of honeydew honeys, melissopalynological analysis was performed following the microscopic method described by Louveaux, Maurizio, and Vorwohl [6]. After classifying and counting pollen (more than 45\% pollen), the samples were tagged as monofloral characteristic. For honeydew honey classification, optic rotation degree was used [1]. 10 monofloral honeys oak, buckweat, pine, heather, chestnut, thyme, rhododendron, ivy, acacia, clover, chastle tree were determined in analyzed honeys (Table 1).

For extraction, $10 \mathrm{~g}$ of the honey was placed with $30 \mathrm{~mL}$ of $70 \%$ ethanol in a glass flask and stirred in an ultrasonicator bath (Heidolph Promax 2020, Schwabach, Germany) at room temperature for $12 \mathrm{~h}$. The suspension was filtered by denser paper and adjusted the final volume with of $70 \%$ ethanol. Even

Table 1 H. pylori growth inhibition, secreted urease, and phenolic contents of ethanolic honey extracts*.

\begin{tabular}{|c|c|c|c|c|c|}
\hline Samples & Location & $\begin{array}{l}\text { Total phenolic contents } \\
\text { mg GAE } / 100 \mathrm{~g}\end{array}$ & $\begin{array}{l}\text { Total flavonoid } \\
\text { contents } \\
\text { mg QE/100 g }\end{array}$ & $\begin{array}{l}\text { Inhibition of } H \text {. pylori } \\
\text { urease } \\
\mathrm{IC}_{50}(\mathrm{mg} / \mathrm{mL})\end{array}$ & $\begin{array}{l}\text { Inhibition zone } \\
(\mathrm{mm})\end{array}$ \\
\hline S1 & Oak/Kırklareli & $68.56 \pm 0.37$ & $4.56 \pm 0.20$ & $9.96 \pm 0.18$ & 32.0 \\
\hline S2 & Buckweat/ Konya & $45.22 \pm 0.55$ & $2.44 \pm 0.05$ & $16.98 \pm 0.13$ & 15.5 \\
\hline S3 & Pine/Mugla & $46.7 \pm 0.252$ & $1.50 \pm 0.30$ & $18.12 \pm 0.16$ & 10.5 \\
\hline S4 & Heather/Canakkale & $72.20 \pm 0.80$ & $6.50 \pm 0.90$ & $8.48 \pm 0.12$ & 35.0 \\
\hline S5 & Chestnut/Balıkesir & $69.60 \pm 0.52$ & $7.08 \pm 0.46$ & $15.76 \pm 0.22$ & 12.0 \\
\hline S6 & Oak/Samsun & $79.0 \pm 0.008$ & $5.60 \pm 0.30$ & $13.99 \pm 0.23$ & 17.5 \\
\hline S7 & Thyme/Denizli & $58.88 \pm 0.01$ & $2.50 \pm 0.40$ & $9.47 \pm 0.18$ & 30.0 \\
\hline S8 & Thyme/Canakkale & $35.90 \pm 0.10$ & $1.78 \pm 0.42$ & $14.91 \pm 0.22$ & 12.5 \\
\hline S9 & Rhododendron/Trabzon & $34.47 \pm 0.41$ & $1.05 \pm 0.08$ & $13.44 \pm 0.09$ & 20.0 \\
\hline $\mathrm{S} 10$ & Ivy/Kırklareli & $45.23 \pm 0.00$ & $4.05 \pm 0.56$ & $2.67 \pm 0.11$ & 60.0 \\
\hline S11 & Acacia/Ordu & $22.10 \pm 0.40$ & $0.95 \pm 0.08$ & $14.12 \pm 0.12$ & 20.0 \\
\hline $\mathrm{S} 12$ & Clover/Çanakkale & $27.60 \pm 0.88$ & $0.88 \pm 0.03$ & $14.42 \pm 0.10$ & 15.0 \\
\hline S13 & Chastle tree/Aydın & $30.25 \pm 0.20$ & $1.10 \pm 0.01$ & $12.05 \pm 0.33$ & 25.0 \\
\hline AA & --- & --- & --- & $25.32 \pm 0.23$ & --- \\
\hline Amoxicillin & --- & --- & --- & --- & 40.0 \\
\hline $70 \%$ Ethanol & --- & --- & --- & --- & 10.0 \\
\hline
\end{tabular}

* Amc $(10 \mu \mathrm{g})$ : Amoxicillin. EtOH. 70\% ethanol was used as control for antimicrobial studies. All honey extracts were tested at $80.00 \mu \mathrm{g} / \mathrm{mL}$ final concentration in anti-H. pylori inhibition test. AA was used standard for urease inhibition and its $\mathrm{IC}_{50}$ value is given as $\mu \mathrm{g} / \mathrm{mL}$. 
though all extract was directly used for antioxidant tests, their concentration has to be adjusted minimal volume as $80 \mu \mathrm{g} / \mathrm{mL}$ for antimicrobial activity.

\subsection{Antimicrobial Activity Assessment}

\subsubsection{Agar Well Diffusion Method}

H. pylori strain J99 was used to determine the antimicrobial activity of honey extracts by agar-well diffusion assay [7]. The bacteria was stored at $-80{ }^{\circ} \mathrm{C}$ in Brucella broth (pH 7.0) with $10 \%$ fetal calf serum supplemented with $20 \%$ glycerol. Brucella agar (7\% horse blood and supplement (DENT)) was used also for H. pylori culture. Supplement (Dent) selective for H. pylori that is containing vancomycin $(10 \mathrm{mg} / \mathrm{liter})$, trime throprim lactate $(5 \mathrm{mg} / \mathrm{L})$, cefsulodin $(5 \mathrm{mg} / \mathrm{L})$, and amphotericin B (5 mg/L), obtained from Oxoid [8]. H. pylori suspension was diluted to approximately $10^{6}$ colony forming unit $(\mathrm{cfu})$ per $\mathrm{mL}$. This was "flood-inoculated" onto the surface of all specific agar plates and then dried. $80 \mu \mathrm{L}$ of the honey extracts were delivered into the wells (five-millimeter diameter). H. pylori cultures were incubated under microaerophilic $\left(5 \% \mathrm{O}_{2}, 10 \% \mathrm{CO}_{2}\right.$, and $\left.85 \% \mathrm{~N}_{2}\right)$ conditions at $37{ }^{\circ} \mathrm{C}$ for up to 7 days. Antimicrobial activity was evaluated by measuring the zone of inhibition against the test organism and ethanol (70\%) was used as the control solvent. The test was applied in triplicates and amoxicillin was used as the standard drug [8].

\subsubsection{H. pylori Growth Medium}

Helicobacter pylori J99 was cultured on Brucella agar (Oxoid, Hampshire, USA) medium with 7\% (v/v) horse blood plus DENT supplement $0.4 \%(\mathrm{v} / \mathrm{v})$ and incubated in a micro aerobic environment at $37^{\circ} \mathrm{C}$ for between 5 and 7 days (GasPak, Oxoid, USA). The bacterial suspensions, containing all colonies grown on Brucella agar medium, were prepared in Brucella broth and adjusted to 2.0 McFarland standard (containing $1 \times 10^{7}$ to $1 \times 10^{8} \mathrm{cfu} / \mathrm{mL}$ ), prepared from a $72 \mathrm{~h}$-old subculture of a blood agar plate.

For urease production, liquid urea broth medium was used that was contained peptone, glucose, $\mathrm{NaCl}$, $\mathrm{KH}_{2} \mathrm{PO}_{4}$ and phenol red indicator [7]. Firstly, the broth was sterilized by autoclaving, then the urea solution filtered $(40 \%, 30 \mathrm{~mL})$ was added to the urea base broth medium $(6 \%, v / v)$, under sterile conditions. The medium was distributed to sterile screwcap bottles, inoculated $1 \mathrm{~mL}\left(1 \times 10^{8} \mathrm{cfu} / \mathrm{mL}\right)$. H. pylori suspension and incubated at $37{ }^{\circ} \mathrm{C}$ between 5 and 7 days with gentle shaking. $H$. pylori is an organism that can be easily identified by this test because of its very high endogenous urease activity $[9,10]$.

\subsubsection{Preparation of $H$. pylori Urease}

The broth cultures were centrifuged $(5.000 \times \mathrm{g}$, $\left.+4{ }^{\circ} \mathrm{C}\right)$ and phosphate-buffered saline $(0.1 \mathrm{M}, \mathrm{pH} 7.4$, PBS) was used to wash for recover bacterial mass and then stored at $-80{ }^{\circ} \mathrm{C}$ until use. Subsequently, the $H$. pylori pellet was thawed to ambient (room) temperature, then mixed with $15 \mathrm{~mL}$ of PBS and protease inhibitors and sonicated for $90 \mathrm{~s}$ in an ice bath. Following centrifugation $(10.000 \mathrm{~g}, 15 \mathrm{~min}$, $4{ }^{\circ} \mathrm{C}$ ), the supernatant was desalted and further concentrated using a centrifugal filter with an Amicon ultra filtration membrane $(10.000 \mathrm{MWCO})$ at $4{ }^{\circ} \mathrm{C}$. One unit of urease activity was described as the amount of enzyme that released $1 \mu \mathrm{M}$ of ammonium per minute at $25{ }^{\circ} \mathrm{C}$ [11]. A calibration curve was prepared with ammonium chloride solution $\left(\mathrm{R}^{2}\right.$ : 0.997). The protein concentration of the enzyme solution $(\mathrm{mg} / \mathrm{mL})$ was determined using the Lowry method [12] with bovine serum albumin standard $\left(\mathrm{R}^{2}\right.$ : 0.998). The urease enzyme solution of $H$. pylori was prepared nearly $1.5-2 \mathrm{U} / \mathrm{mg}$ protein, to use in inhibition studies.

\subsubsection{Urease Inhibition Assay}

In this inhibition method, ammonia can be detected by its reaction with phenol hypochlorite at high $\mathrm{pH}$ from indophenol blue [13]. The inhibition potency was measured by UV spectroscopy technique at 625 $\mathrm{nm}$ by using a UV/VIS spectrophotometer (1601UV-Shimadzu, Australia). A positive control was acetohydroxamic acid (AA) used. The reaction 
mixture comprising $500 \mu \mathrm{L}$ of buffer $(100 \mathrm{mM}$ urea, $0.01 \mathrm{M} \mathrm{K}_{2} \mathrm{HPO}_{4}, 1 \mathrm{mM}$ EDTA and $0.01 \mathrm{M} \mathrm{LiCl}, \mathrm{pH}$ 8.2), $200 \mu \mathrm{L}$ of urease enzyme solution and honey extract $(200 \mu \mathrm{L}$, only those extracts that exhibited activity against $H$. pylori) were subjected to incubation for $15 \mathrm{~min}\left(30^{\circ} \mathrm{C}\right)$ in test tubes. After incubation, a phenol reagent $(500 \mu \mathrm{L}, 1 \% \mathrm{w} / \mathrm{v}$ phenol and $0.005 \% \mathrm{w} / \mathrm{v}$ sodium nitroprusside) and an alkali reagent $(600 \mu \mathrm{L}, 0.5 \% \mathrm{w} / \mathrm{v}$ sodium hydroxide and $0.1 \% \mathrm{v} / \mathrm{vNaOCl})$ were added to each tube. Results were expressed as the $\mathrm{IC}_{50}$ values which were the inhibition concentration of the hydrolysis of $50 \%$ of the substrate were determined from the dose response curve.

2.3.5 Total Phenolic Content (TPC) and Total Flavonoid Content (TFC)

Total phenolic contents of the methanolic honey extract were measured by the Folin-Ciocalteu's method [14] as used gallic acid standard. The result was expressed as $\mathrm{mg}$ of gallic acid equivalents per $\mathrm{g}$ sample. The quantity of total flavonoid was measured by the spectrometric assay [15] using quercetin standard. Its results were defined as mg of quercetin equivalents per $100 \mathrm{~g}$ sample.

\section{Result and Discussion}

H. pylori has managed to colonize the highly acidic environment found within the stomach by breaking down urea to ammonia via urease, which generates a neutral environment enveloping the bacterium [16]. Its inhibition is very important for the treatment of $H$. pylori-related diseases. There are so many in vivo and in vitro studies for reducing the risk of $H$. pylori of peptic ulcers and gastric cancer. Beside these study developments, it is possible to encounter with some obstructions one of which is drug resistance. Liu et al. [4] and Rasheed et al. [5] have been reported that there was an increasing rate of $H$. pylori strains with primary resistance to nitroimidazoles and clarithromycin. Also, the drug combination that was a proton pump inhibitor (PPI) and two antibiotics (amoxicillin and clarithromycin) has been recommended to fight off this chronic infection since the fall of 2012 [17]. Zemali et al.'s [18] study was focused on a mutation of ribosamal target. When this combination was used, it was the existence of a primary resistance to clarithromycin which was the main reason for therapeutic failure. Hence it could be concluded that there is a need for treatment perspective with alternative natural compounds such as plant materials, bee products.

Bee products are a huge family with honey, pollen, propolis, and royal jelly which are used for apitherapy. The medicinal use of honey bee products has been practiced since ancient times [19]. While there have been many general antimicrobial searches against different strains, anti-H. pylori has limited. Khalil et al. [19] demonstrated that several processed and raw honey samples collected from north-west Pakistani sources had significant antibacterial properties with six Gram-negative and six Gram-positive bacterial strains. Directly $H$. pylori inhibition studies have to be given to correlate the present results. One of them was the in vitro assessment of helicobacter pylori urease inhibition by honey fractions. After evaluating of the experiment, the effects of honey extracts on $H$. pylori urease had showed a concentration-dependent response and finally, at $100 \%$, honey extract $\sim 48 \%$ inhibition to $H$. pylori urease activity [8].

The $\mathrm{IC}_{50}$ values of the current study were expressed as $\mathrm{mg} / \mathrm{mL}$ for Inhibition of $H$. pylori urease and also inhibition zone were mm (Table 1). Sahin [20] studied with 12 honey samples for evaluating new natural inhibitor source for the urease. It was found the urease inhibition activity $\mathrm{IC}_{50}$ values as $12-21 \mathrm{mg} / \mathrm{mL}$. Our $\mathrm{IC}_{50}$ values of inhibition of $H$. pylori urease ranged from 2.67 to $18.12 \mathrm{mg} / \mathrm{mL}$. The lowest value could be evaluated as the strongest was observed in ivy honey $(2.67 \pm 0.11)$ from Kirklareli with S10 number. All the other honeys had $\mathrm{IC}_{50}$ value $<25.32 \pm 0.23$ which was acetohydroxamic acid (AA) standard. On the other hand the inhibition zone of the processed honeys 
ranged from $10.5 \mathrm{~mm}$ to $60 \mathrm{~mm}$. Similar to the inhibition of $H$. pylori urease, S10 had the most efficient among the processed honeys with $60 \mathrm{~mm}$ inhibition zone. Manyi-Loh et al. [21] searched the anti-H. pylori activity from selected South African honeys extract using n-hexane, diethyl ether, chloroform, ethyl acetate and determined the MICs of the extracts ranged from 15.8-18.8 $\mathrm{mm}$ (mean $\pm \mathrm{SD}$ ). It was noteworthy that our efficient value was more remarkable than the giving study and amoxicillin. Moreover amoxicillin is still very effective in the treatment of $H$. pylori infection and remains a treatment of choice among other drugs [8]. It could be concluded that ivy honey sample could have one or multi active substances. Besides ivy honey sample, heather honey from Canakkale had the assertive value with $8.48 \pm 0.12 \mathrm{mg} / \mathrm{mL} \mathrm{IC}_{50}$ and $35 \mathrm{~mm}$ inhibition zone. It cannot make a simple criticism as they are honey. Each sample has different compounds which are endowed with numerous biomedical activities including antimicrobial, antioxidant effects [22]. Evidence based data clearly indicated honeys content as well as active compounds depend on floral and geographic origins [23].

Thereby, it may be reached a conclusion such as honey intake is associated with reduced prevalence of H. pylori infection. This claim was supported by Boyanova et al. [24]. They have examined endoscopically and by the urea breath test in 150 consecutive untreated dyspeptic patients. After investigation, they revealed that $H$. pylori infection of positivity rate was lower in patients consuming honey $\geq 1$ day weekly compared with the remainder patients.

Phenolics and flavonoids have so many members known as secondary metabolites and bioactive compounds in plants and natural products. These bioactive compounds play important role to control of different human diseases. Due to irregular electron transfer in metabolism or environmental risk factors, free radicals occur in human system. Unfortunately, free radicals cause some health problems which include cancer, heart diseases and gastric problems etc. [2]. Briefly, bioactive substances that are effective in reducing the health risks may protect cells from the damage caused by reactive free radicals. In the light of this reality, TPC and TFC were analyzed for all honeys and the data were presented in Table 1. In the current study, the oak honey (S6) had the highest (79.00 $\pm 0.008 \mathrm{mg} \mathrm{GAE} / 100 \mathrm{~g}$ sample) TPC followed by S4 (heather) and S5 (chestnut), while S11 (acacia honey) had the lowest $(22.10 \pm 0.40 \mathrm{mg} \mathrm{GAE} / 100 \mathrm{~g}$ sample) total phenolic content followed by S12 (clover honey) and S13 (castle tree honey) (Table 1). When compared to other studies, 62 honey samples including 11 unifloral honeys (chestnut, heather, chaste tree, rhododendron, common eryngo, lavender, Jerusalem tea, astragalus, clover and acacia), total phenolic contents between $16.02 \pm 2.70$ and $120.04 \pm 18.56 \mathrm{mg}$ GAE/100 g were found [1]. In the same study was reported that the oak sample was the highest level TPC similar to our result. The mono- and poly-floral studied shown total phenolic content values $<9 \mathrm{mg}$ GAE/100 g honey. TPC levels of the honeys between 9.400 to $65.000 \mathrm{mg} \mathrm{GAE} / 100 \mathrm{~g}$ sample were reported [20]. Besides total phenolic, total flavonoid content values in the investigated honey samples varied in the range of $0.88-7.08 \mathrm{mg} \mathrm{QE} / 100 \mathrm{~g}$ sample were moderate level when compared to literature. S5 (chestnut honey) and S4 (heather honey) had so highly TFC degree with $7.08 \pm 0.46-6.50 \pm 0.90 \mathrm{mg} \mathrm{QE} / 100$ g honey, respectively. According to the TPC and TFC values, a reality came again about the correlation between color and TPC-TFC values of honeys. It was associated with the color of the honey where darker honeys have higher TPC and TFC [25]. Our study supported this claim with experiment results that oak, heather, chestnut were darker honey detected high TPC and TFC levels.

\section{Conclusion}

In conclusion, the current study could be an evidence for treatment in $H$. pylori with some new 
monofloral tagged honey sexhibited their inhibitory effects against this bacterium. Some of them showed so highly effect both urease inhibition and total phenolic - total flavonoid contents such as ivy and heather honeys. Also, the study was the first study reporting about ivy honey which was the best value of urease inhibition. It was a claim that the high variability of total phenolic and flavonoid content concentration made impossible to characterize of the honey type. But this claim could help for giving an idea for inhibition degree. Because, TPC and TFC were nearly correlated with urease inhibition degree.

\section{Acknowledgments}

This study was supported by the Tubitak project (114Z370).

\section{Conflict of Interests}

The authors report no financial or other conflict of interest relevant to the subject of this article.

\section{References}

[1] Can, Z., Yildiz, O., Sahin, H., Akyuz Turumtay, E., Silici, S., and Kolayli, S. 2015. "An Investigation of Turkish Honeys: Their Physico-Chemical Properties, Antioxidant Capacities and Phenolic Profiles." Food Chemistry 180: 133-41.

[2] Yousuf, F. A., Mehmood, M. H., Malik, A., Siddiqui, R., and Khan, N. A. 2016. "Antiacanthamoebic Properties of Natural and Marketed Honey in Pakistan." Asian Pacific Journal of Tropical Biomedicine 6 (11): 967-72.

[3] Shi, J., Jiang, Y., and Zhao, Y. 2016. "Promising in Vitro and in Vivo Inhibition of Multidrug-Resistant Helicobacter Pylori by Linezolid and Novel Oxazolidinone Analogues." Journal of Global Antimicrobial Resistance 7: 106-9.

[4] Liu, G., Xu, X., He, L., Ding, Z., Gu, Y., Zhang, J., and Zhou, L. 2011. "Primary Antibiotic Resistance of Helicobacter Pylori Isolated from Beijing Children." Helicobacter 16 (5): 356-62.

[5] Rasheed, F., Campbell, B. J., Alfizah, H., Varro, A., Zahra, R., Yamaoka, Y., and Pritchard, D. M. 2014. "Analysis of Clinical Isolates of Helicobacter Pylori in Pakistan Reveals High Degrees of Pathogenicity and High Frequencies of Antibiotic Resistance." Helicobacter 19 (5): 387-99.

[6] Louveaux, J., Maurizio, A., and Vorwohl, G. 1978.
"Methods of Melissopalynology." Bee World 59 (4): 139-57.

[7] Baltas, N., Karaoglu, S. A., Tarakci, C., and Kolayli, S. 2016. "Effect of Propolis In Gastric Disorders: Inhibition Studies on the Growth of Helicobacter Pylori and Production of Its Urease." Journal of Enzyme Inhibition and Medicinal Chemistry, 1-5.

[8] Matongo, F., and Nwodo, U. U. 2014. "In Vitro Assessment of Helicobacter Pylori Ureases Inhibition by Honey Fractions." Archives of Medical Research 45 (7): 540-6.

[9] Klein, P. D., Graham, D. Y., Gaillour, A., Opekun, A. R., and Smith, E. O. 1991. "Water Source as Risk Factor for Helicobacter Pylori Infection in Peruvian Children. Gastrointestinal Physiology Working Group." Lancet (London, England) 337 (8756): 1503-6.

[10] Vincent, P., Gottrand, F., Pernes, P., Husson, M. O., Lecomte-Houcke, M., Turck, D., and Leclerc, H. 1994. "High Prevalence of Helicobacter Pylori Infection in Cohabiting Children. Epidemiology of a Cluster, with Special Emphasis on Molecular Typing." Gut: 35 (3): 313-6.

[11] Brdanin, S., Bogdanović, N., Kolundžić, M., Milenković, M., Golić, N., Kojić, M., and Kundaković, T. 2015. "Antimicrobial Activity of Oregano (Origanum vulgare L.) and Basil (Ocimum basilicum L.) Extracts." Advanced Technologies 4 (2): 5-10.

[12] Lowry, O. H., Rosebrough, N. J., Farr, A. L., and Randall, R. J. 1951. "Protein Measurement with the Folin Phenol Reagent." Journal of Biological Chemistry 193: 265-75.

[13] Weatherburn, M. W. 1967. "Phenol-Hypochlorite Reaction for Determination of Ammonia." Analytical Chemistry 39 (8): 971-4.

[14] Singleton, V. L., Orthofer, R., and Lamuela-Raventós, R. M. 1999. "Analysis of Total Phenols and Other Oxidation Substrates and Antioxidants by Means of Folin-Ciocalteu Reagent." Methods in Enzymology 299: 152-78.

[15] Fukumoto, L. R., and Mazza, G. 2000. "Assessing Antioxidant and Prooxidant Activities of Phenolic Compounds." Journal of Agricultural and Food Chemistry 48 (8): 3597-604.

[16] Wroblewski, L. E., Peek, R. M., Wilson, K. T., and Wilson, K. T. 2010. "Helicobacter Pylori and Gastric Cancer: Factors That Modulate Disease Risk." Clinical Microbiology Reviews 23 (4): 713-39.

[17] Malfertheiner, P., Megraud, F., O’Morain, C., Bazzoli, F., El-Omar, E., Graham, D., and Kuipers, E. J. 2007. "Current Concepts in the Management of Helicobacter Pylori Infection: The Maastricht III Consensus Report." Gut 56 (6): 772-81.

[18] Zemali, N., Guillemot, G., Jaubert, J., Picot, S., Thomas, E., Becquart, J. P., and Kwiatek, S. 2016. "Helicobacter 
Pylori Resistance to Clarithromycin in Reunion Island.” Médecine et Maladies Infectieuses 46 (7): 385-9.

[19] Khalil, A. T., Khan, I., Ahmad, K., Khan, Y. A., Khan, J., and Shinwari, Z. K. 2014. "Antibacterial Activity of Honey in North-West Pakistan against Select Human Pathogens." Journal of Traditional Chinese Medicine 34 (1): 86-9.

[20] Sahin, H. 2016. "Honey as an Apitherapic Product: Its Inhibitory Effect on Urease and Xanthine Oxidase." Journal of Enzyme Inhibition and Medicinal Chemistry 31 (3): 490-4.

[21] Manyi-Loh, C. E., Clarke, A. M., Munzhelele, T., Green, E., Mkwetshana, N. F., and Ndip, R. N. 2010. "Selected South African Honeys and Their Extracts Possess in Vitro Anti-Helicobacter Pylori Activity." Archives of Medical Research 41 (5): 324-31.

[22] Manyi-Loh, C. E., Clarke, A. M., and Ndip, R. N. 2012.
"Detection of Phytoconstituents in Column Fractions of n-Hexane Extract of Goldcrest Honey Exhibiting Anti-Helicobacter Pylori Activity." Archives of Medical Research 43 (3): 197-204.

[23] Küçük, M., Kolaylı, S., Karaoğlu, Ş., Ulusoy, E., Baltacı, C., and Candan, F. 2007. "Biological Activities and Chemical Composition of Three Honeys of Different Types from Anatolia." Food Chemistry 100 (2): 526-34.

[24] Boyanova, L., Ilieva, J., Gergova, G., Vladimirov, B., Nikolov, R., and Mitov, I. 2015. "Honey and Green/Black Tea Consumption May Reduce The Risk of Helicobacter Pylori Infection.” Diagnostic Microbiology and Infectious Disease 82 (1): 85-6.

[25] Serem, J. C., and Bester, M. J. 2012. "Physicochemical Properties, Antioxidant Activity and Cellular Protective Effects of Honeys from Southern Africa." Food Chemistry 133 (4): 1544-50. 